\title{
The efficacy and safety of dutasteride compared with finasteride in treating men with androgenetic alopecia: a systematic review and meta-analysis
}

This article was published in the following Dove Medical Press journal: Clinical Interventions in Aging

\author{
Zhongbao Zhou',2,* \\ Shiqiang Song ${ }^{3, *}$ \\ Zhenli Gao ${ }^{2}$ \\ Jitao $\mathrm{Wu}^{2}$ \\ Jiajia $\mathrm{Ma}^{2}$ \\ Yuanshan $\mathrm{Cui}^{2}$
}

'School of Clinical Medicine, Binzhou Medical University, Yantai, Shandong, China; ${ }^{2}$ Department of Urology, The Affiliated Yantai Yuhuangding Hospital of Qingdao University, Yantai, Shandong, China; ${ }^{3}$ Department of Urology, Qingdao Chengyang People's Hospital, Qingdao, Shandong, China

*These authors contributed equally to this work
Correspondence: Yuanshan Cui Department of Urology, The Affiliated Yantai Yuhuangding Hospital of Qingdao University, No 20 East Yuhuangding Road, Yantai 264000, Shandong, China $\mathrm{Tel} / \mathrm{fax}+865356695579$ Email mI52755253I6@I63.com
Aim: We performed a meta-analysis to evaluate the efficacy and safety of dutasteride and finasteride in treating men with androgenetic alopecia (AGA) during a 24-week treatment cycle. Methods: Randomized controlled trials of dutasteride and finasteride for treating AGA were searched using MEDLINE, EMBASE, and the Cochrane Controlled Trials Register. The data were calculated using Rev Man v5.3.0. The reference lists of retrieved studies were also investigated.

Results: Three articles including 576 participants which compared dutasteride with finasteride were selected for our analysis. The mean change in total hair count (mean difference [MD], 28.57; 95\% CI, 18.75-38.39; $P<0.00001$ ), investigator's assessment of global photographs for the vertex (MD, 0.68; 95\% CI, 0.13-1.23; $P=0.02)$ and frontal (MD, $0.63 ; 95 \% \mathrm{CI}$, $0.13-1.13 ; P=0.01)$ views, panel global photographic assessment for the vertex (MD, 0.17 ; 95\% CI, 0.09-0.24; $P<0.00001)$ and frontal (MD, 0.25; 95\% CI, 0.18-0.31; $P<0.00001$ ) views, and subjects' assessment (MD, 0.56; 95\% CI, 0.18-0.94; $P=0.003$ ) suggested that dutasteride provided a better efficacy in treating men with AGA compared with finasteride. With regard to the assessment of safety, altered libido $(P=0.54)$, erectile dysfunction $(P=0.07)$, and ejaculation disorders $(P=0.58)$, dutasteride did not show a significant difference compared with finasteride.

Conclusion: Dutasteride seems to provide a better efficacy compared with finasteride in treating AGA. The two drugs appear to show similar rates of adverse reactions, especially in sexual dysfunction.

Keywords: androgenetic alopecia, meta-analysis, randomized controlled trials, dutasteride, finasteride

\section{Introduction}

Male androgenetic alopecia (AGA), as the most common type of baldness, is an androgen-dependent inherited hair loss, which has a significant impact on patient's psychological condition. ${ }^{1,2}$ Hair loss starts mostly from the hairline on both sides of the forehead and gradually expands upward, eventually leading the hair to fall off at the top of the head. ${ }^{3,4}$

Testosterone is the main androgen in the circulation, but to exert maximum activity in the hair follicles of the scalp, it must first be converted to dihydrotestosterone (DHT) which is the principal pathogenic androgen of AGA by the catalysis of enzyme 5-alpha reductase (5AR). ${ }^{5}$ Finasteride, an oral type 2 -alpha reductase inhibitor (5ARI), has been approved by the US Food and Drug Administration for the treatment of AGA, significantly reversing the process of hair loss and increasing the length and density 
of the targeted hair. ${ }^{6,7}$ Observing related literature on the effectiveness of finasteride in AGA, as many as 30\%-45\% of participants did not show relief of clinical symptoms which were eventually hard to control. ${ }^{8}$ Although hair above the head is no longer shed after the treatment of finasteride, patient's target for treatment is not only to delay the progression of AGA, but also to increase the amount of the targeted hair and improve patients' quality of life. ${ }^{9}$

Recently, dutasteride, a dual 5ARI, has been used for the treatment of AGA in the clinic, showing a different mechanism and strong therapeutic effect. ${ }^{10}$ Dutasteride may provide an alternative treatment for men with AGA after the inconspicuous efficacy of finasteride. Currently, there is not enough evidence to show the merit and demerit of the two drugs.

We performed a meta-analysis to evaluate the efficacy and safety of dutasteride and finasteride in treating AGA during a 24-week treatment cycle.

\section{Materials and methods Study design}

A systematic review of randomized controlled trials (RCTs) was carried out using the PRISMA ${ }^{11}$ checklist.

\section{Search strategy}

We searched MEDLINE (1990 to August 2018), EMBASE (1995 to August 2018), and the Cochrane Controlled Trials Register to collect studies investigating dutasteride vs finasteride in treating men with AGA. The search formula was as follows: "dutasteride, finasteride, androgenetic alopecia, and RCT". The authors were contacted to offer further information from their research if necessary. Furthermore, we also searched the reference list of related articles.

\section{Inclusion criteria and trial selection}

RCTs that met the following criteria were included: 1) dutasteride vs finasteride in treating men with AGA; 2) the full-text of study was gettable; and 3 ) the study provided accurate data that could be analyzed, mainly including the total number of subjects and the valuable results of each indicator. If the identical experiment was published in different journals or at different time, the latest study was included in the metaanalysis. If the same group of researchers studied a group of subjects with multiple experiments, then each study was included. The flow diagram of selection process is shown in Figure 1.

\section{Quality assessment}

The Jadad scale was used to evaluate the quality of each study. ${ }^{12}$ All the retrieved RCTs were included in the study

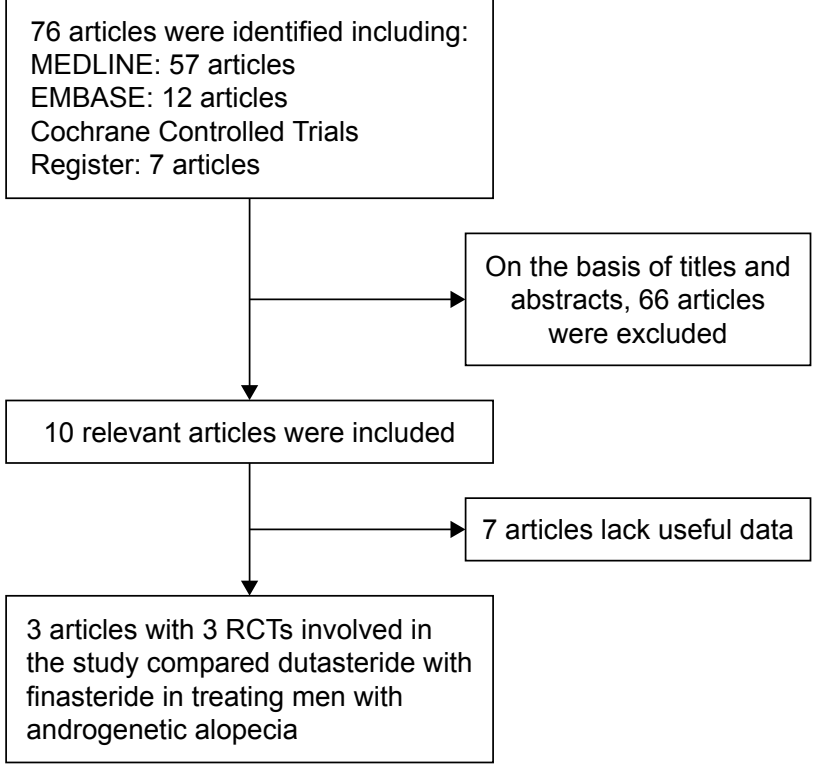

Figure I Flowchart of the study selection process. Abbreviation: RCT, randomized controlled trial.

regardless of the quality score. The methods of quality assessment, including method of patient allocation, concealment of allocation, blinding method, and number lost to follow-up, were used to analyze the quality of individual study. Each study was graded on the basis of guidelines published in the Cochrane Handbook for Systematic Reviews of Interventions v5.30. ${ }^{13}$ The study was evaluated and classified based on quality assessment criteria: A, satisfied all quality criteria and had a low risk of bias; $\mathrm{B}$, ambiguous about one or more quality criteria and had a moderate risk of bias; or C, barely met the quality criteria and had a high risk of bias. Differences regarding the quality assessment were resolved by discussion among the researchers.

\section{Data extraction}

The following information was collected for each study: publication time, name of the first author, patient's received therapy, capacity of sample, the mean change in total hair count, investigator's assessment of global photographs for the vertex and frontal views, panel global photographic assessment for the vertex and frontal views, subjects' assessment, altered libido, erectile dysfunction (ED), and ejaculation disorders.

\section{Statistical analyses and meta-analysis}

The data were calculated by using Rev Man v5.3.0 (Cochrane Collaboration, Oxford, UK). ${ }^{13}$ We analyzed the change of total hair count, investigator's assessment of global photographs for the vertex and frontal views, panel global photographic assessment for the vertex and frontal views, and 
subjects' assessment between dutasteride and finasteride in treating men with AGA during a 24-week treatment cycle. In addition, the number of cases of altered libido, ED, and ejaculation disorders was also counted. The mean difference (MD) was used to evaluate continuous outcomes and dichotomous outcomes were assessed by OR. We analyzed comparable data using 95\% CIs. ${ }^{14}$ The indicator could be characterized as fixed-effects model if $P>0.05$, or otherwise, a random-effects model was used. We analyzed inconsistency using the $I^{2}$ statistic, which reflected the proportion of heterogeneity across trails.

\section{Results}

\section{Characteristics of individual studies}

Our search strategy found 76 articles. After scrutinizing their abstracts and titles, we ruled out 66 articles. Of the remaining ten articles, seven articles were excluded due to lack of effective data. Finally, three articles containing three RCTs ${ }^{15-17}$ that analyzed dutasteride vs finasteride in treating men with AGA were included in our study. The baseline characteristics of three studies are summarized in Table 1.

\section{Quality of the individual studies}

All RCTs showed the randomization and double-blinded processes. All studies performed a calculation to obtain the optimal sample size, and two studies used intention-to-treat analysis. The quality level of each study was A (Table 2). The plot was highly symmetrical and three squares were contained in the large triangle, and no evidence of bias was found (Figure 2).

\section{Efficacy}

The mean change in total hair count

Three RCTs enrolling 576 patients (290 in the dutasteride group and 286 in the finasteride group) contained data on the mean change in total hair count (Figure 3). A random-effects model was used to assess these RCTs, the MD was 28.57 and 95\% CI was $18.75-38.39(P<0.00001)$. Hence, this result suggested that dutasteride showed significant increase in the total hair count compared with finasteride.

\section{Investigator's assessment of global photographs for the vertex and frontal views}

Three RCTs enrolling 576 patients (290 in the dutasteride group and 286 in the finasteride group) contained data on the investigator's assessment of global photographs (Figure 3). For the vertex views, a random-effects model showed an MD of 0.68 and $95 \% \mathrm{CI}$ of $0.13-1.23(P=0.02)$. At the frontal scalp, the MD was 0.63 and $95 \%$ CI was $0.13-1.13(P=0.01)$.

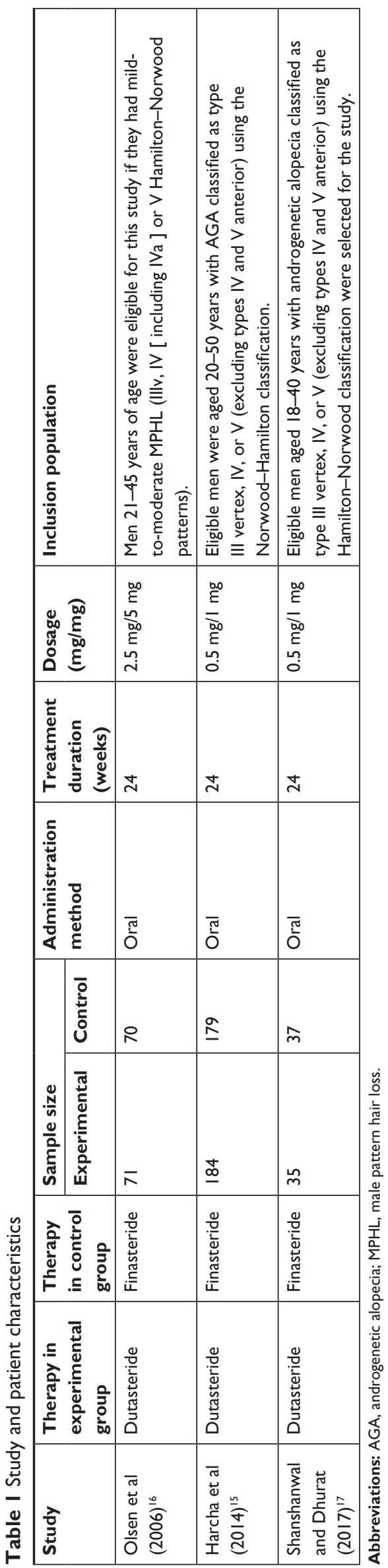


Table 2 Quality assessment of individual study

\begin{tabular}{|c|c|c|c|c|c|c|c|c|}
\hline Study & $\begin{array}{l}\text { Allocation } \\
\text { sequence } \\
\text { generation }\end{array}$ & $\begin{array}{l}\text { Allocation } \\
\text { concealment }\end{array}$ & Blinding & $\begin{array}{l}\text { Loss to } \\
\text { follow-up }\end{array}$ & $\begin{array}{l}\text { Calculation of } \\
\text { sample size }\end{array}$ & $\begin{array}{l}\begin{array}{l}\text { Statistical } \\
\text { analysis }\end{array} \\
\end{array}$ & $\begin{array}{l}\text { Level of } \\
\text { quality }\end{array}$ & $\begin{array}{l}\text { ITT } \\
\text { analysis }\end{array}$ \\
\hline Olsen et al $(2006)^{16}$ & A & A & A & 6 & Yes & ANCOVA & A & Yes \\
\hline Harcha et al $(2014)^{15}$ & $A$ & $A$ & A & 20 & Yes & ANCOVA & $A$ & Yes \\
\hline Shanshanwal and Dhurat $(2017)^{17}$ & $A$ & B & A & 11 & Yes & ANCOVA & A & No \\
\hline
\end{tabular}

Abbreviations: A, all quality criteria met (adequate): low risk of bias; $B$, one or more quality criteria met (moderate): moderate risk of bias; ITT, intention-to-treat; ANCOVA, analysis of covariance.

This result suggested that dutasteride showed statistical differences in the investigator's assessment of global photographs for the vertex and frontal views compared with finasteride.

Panel global photographic assessment for the vertex and frontal views

Two RCTs enrolling 504 patients (255 in the dutasteride group and 249 in the finasteride group) (Figure 3) contained data on the panel global photographic assessment. For the vertex views, a fixed-effects model showed that the MD was 0.17 and $95 \%$ CI was $0.09-0.24(P<0.00001)$. At the frontal scalp, the MD was 0.25 and $95 \%$ CI was $0.18-0.31$ $(P<0.00001)$. We found significant differences between the dutasteride group and finasteride group in the panel global photographic assessment for the vertex and frontal views.

\section{Subjects' assessment}

Three RCTs enrolling 576 patients (290 in the dutasteride group and 286 in the finasteride group) (Figure 3) contained data on the subjects' assessment. The heterogeneity test showed $P=0.02$, so we adopted the random-effects model,

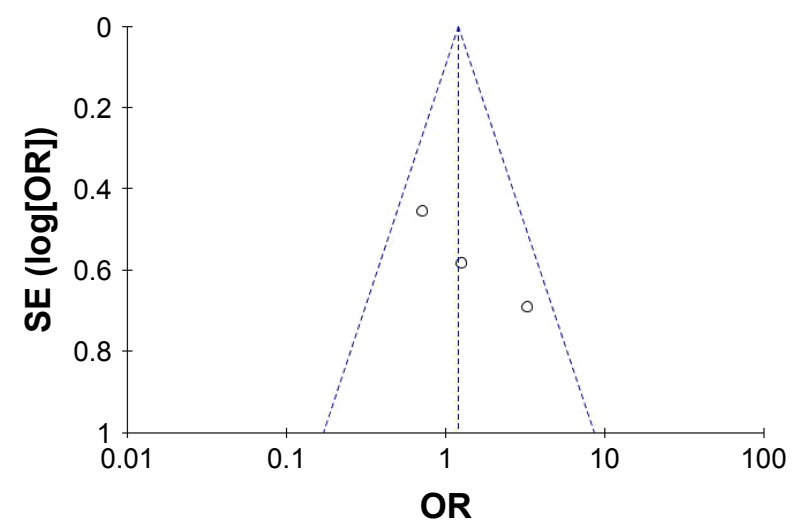

Figure 2 Funnel plot of the studies included in our meta-analysis. Abbreviation: SE, standard error. the MD was 0.56 and $95 \%$ CI was $0.18-0.94(P=0.003)$. We found statistical differences between the dutasteride group and finasteride group in the subjects' assessment.

\section{Safety}

\section{Altered libido}

Three RCTs involving 576 participants (290 in the dutasteride group and 286 in the finasteride group) (Figure 4) contained data on altered libido. The heterogeneity test showed $P=0.18$, so we chose the fixed-effects model, the $95 \%$ CI was $0.66-2.20$ and the OR was $1.12(P=0.54)$. The result showed that there were no statistical differences in terms of altered libido between the two groups.

\section{Erectile dysfunction}

Two RCTs involving 435 participants contained data on ED (219 in the dutasteride group and 216 in the finasteride group) (Figure 4). A fixed-effects model showed an OR of 1.18 and 95\% CI of $0.52-2.68(P=0.70$ ), which showed no significant differences in the ED between the two groups.

\section{Ejaculation disorders}

Two RCTs involving 504 participants (255 in the dutasteride group and 249 in the finasteride group) (Figure 4) contained data on ejaculation disorders. A fixed-effects model revealed an OR of 0.75 and $95 \% \mathrm{CI}$ of $0.28-2.05(P=0.58)$. The result showed that the dutasteride group showed no statistical differences in ejaculation disorders compared with the finasterid group.

\section{Discussion}

AGA, a multifactorial skin disease with a complex genetic inheritance, is characterized by a progressive shedding of visible terminal hair. ${ }^{18}$ DHT is the vital pathogenic factor in AGA, which results in miniaturization of hair follicles and conversion of terminal hair into vellus hair., ${ }^{49}$ Without treatment, patients will suffer from progressive hair 


\begin{tabular}{|c|c|c|c|c|c|c|c|c|c|}
\hline $\begin{array}{l}\text { Study or } \\
\text { subgroup }\end{array}$ & $\begin{array}{l}\text { Dutast } \\
\text { Mean }\end{array}$ & $\begin{array}{l}\text { eride } \\
\text { SD }\end{array}$ & Total & $\begin{array}{l}\text { Finast } \\
\text { Mean }\end{array}$ & $\begin{array}{c}\text { eride } \\
\text { SD }\end{array}$ & Total & $\begin{array}{l}\text { Weight } \\
\text { (\%) }\end{array}$ & $\begin{array}{l}\text { Mean difference } \\
\text { IV, random, } 95 \% \mathrm{CI}\end{array}$ & \\
\hline Olsen EA 2006 & 109.6 & 24.73 & 71 & 75.6 & 21.28 & 70 & 30.0 & $34.00(26.39,41.61)$ & \\
\hline VG 2014 & 89.6 & 6.18 & 184 & 56.5 & 5.81 & 179 & 36.4 & $33.10(31.87,34.33)$ & \\
\hline Dhurat RS 2017 & 23.1 & 8.44 & 35 & 4.3 & 12.46 & 37 & 33.6 & $18.80(13.91,23.69)$ & \\
\hline Total $(95 \% \mathrm{Cl})$ & & & 290 & & & 286 & 100 & $28.57(18.75,38.39)$ & \\
\hline
\end{tabular}

Test for overall effect: $Z=5.70(P<0.00001)$

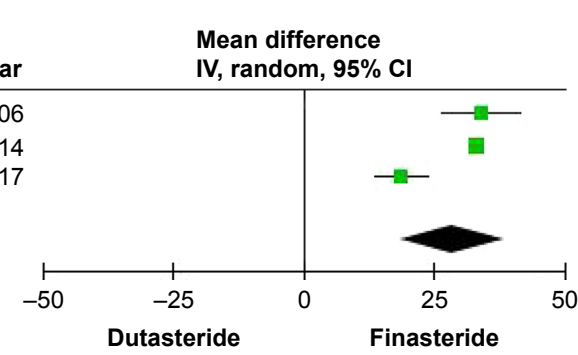

\begin{tabular}{|c|c|c|c|c|c|c|c|c|}
\hline $\begin{array}{l}\text { Study or } \\
\text { subgroup }\end{array}$ & $\begin{array}{l}\text { Dutast } \\
\text { Mean }\end{array}$ & $\begin{array}{l}\text { eride } \\
\text { SD }\end{array}$ & Total & $\begin{array}{l}\text { Finast } \\
\text { Mean }\end{array}$ & $\begin{array}{l}\text { eride } \\
\text { SD }\end{array}$ & Total & $\begin{array}{l}\text { Weight } \\
(\%)\end{array}$ & $\begin{array}{l}\text { Mean difference } \\
\mathrm{IV} \text {, random, } 95 \% \mathrm{CI}\end{array}$ \\
\hline Olsen EA 2006 & 1.85 & 1.01 & 71 & 1.21 & 0.94 & 70 & 33.6 & $0.64(0.32,0.96)$ \\
\hline Harcha WG 2014 & 1.3 & 0.83 & 184 & 1.07 & 0.87 & 179 & 36.5 & $0.23(0.05,0.41)$ \\
\hline Dhurat RS 2017 & 2.23 & 0.81 & 35 & 0.95 & 1.18 & 37 & 29.9 & $1.28(0.81,1.75)$ \\
\hline Total $(95 \% \mathrm{Cl})$ & & & 290 & & & 286 & 100 & $0.68(0.13,1.23)$ \\
\hline
\end{tabular}

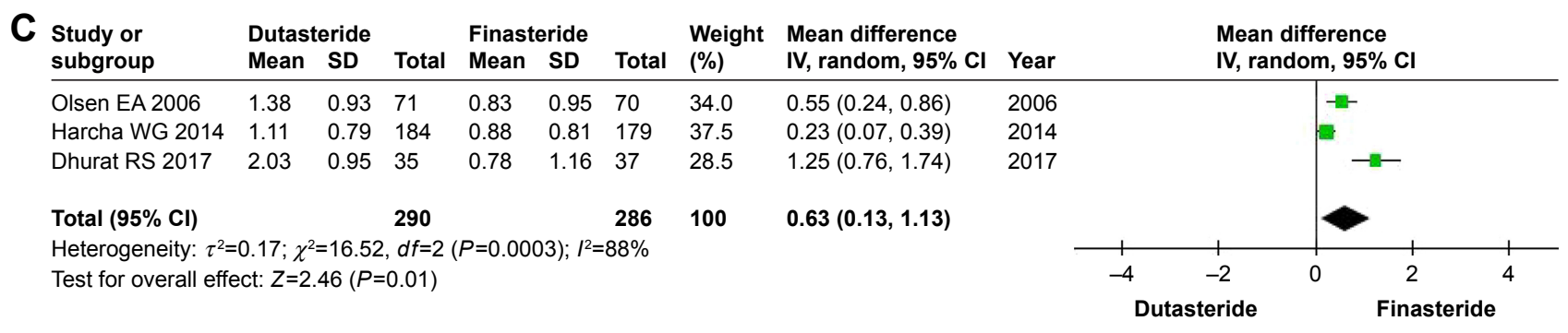

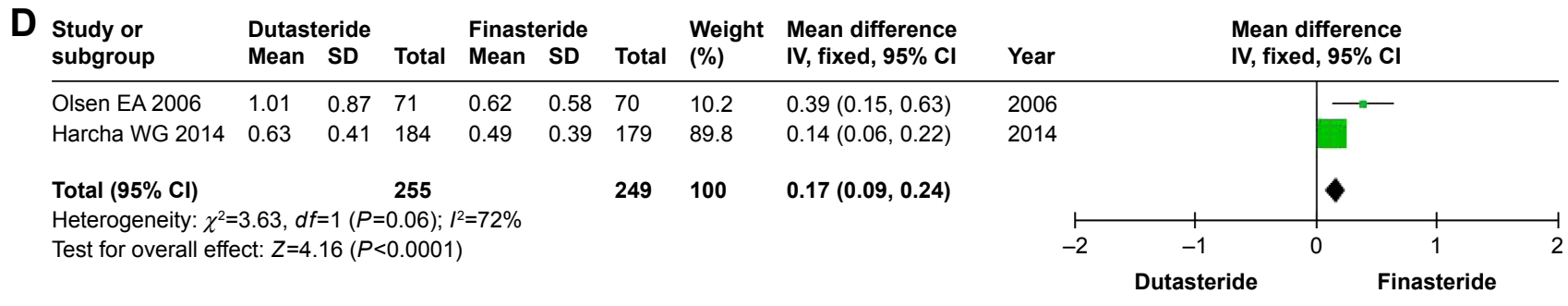

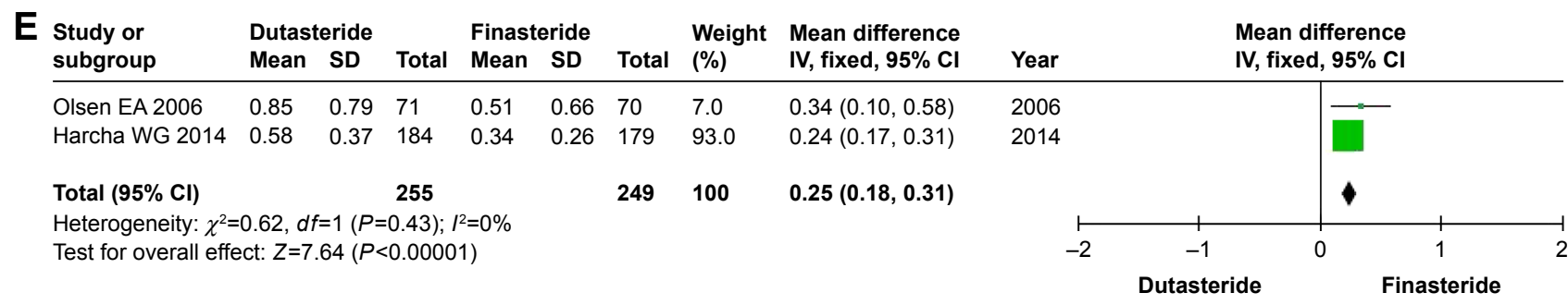

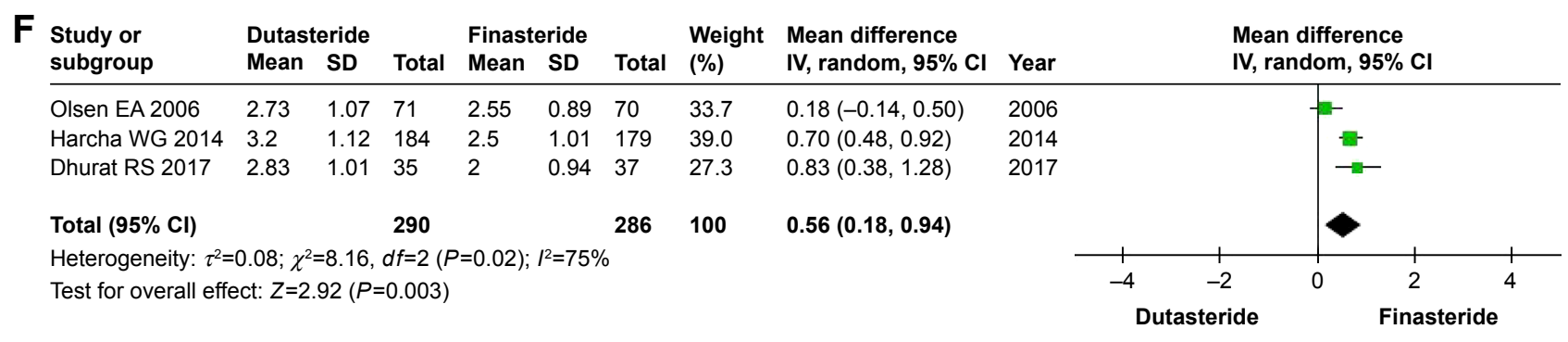

Figure 3 Forest plots showing changes in (A) the mean change in total hair count, (B) investigator's assessment of global photographs for the vertex views, (C) investigator's assessment of global photographs for the frontal views, (D) panel global photographic assessment for the vertex views, (E) panel global photographic assessment for the frontal views, and $(\mathbf{F})$ subjects' assessment.

Abbreviation: IV, inverse variance. 


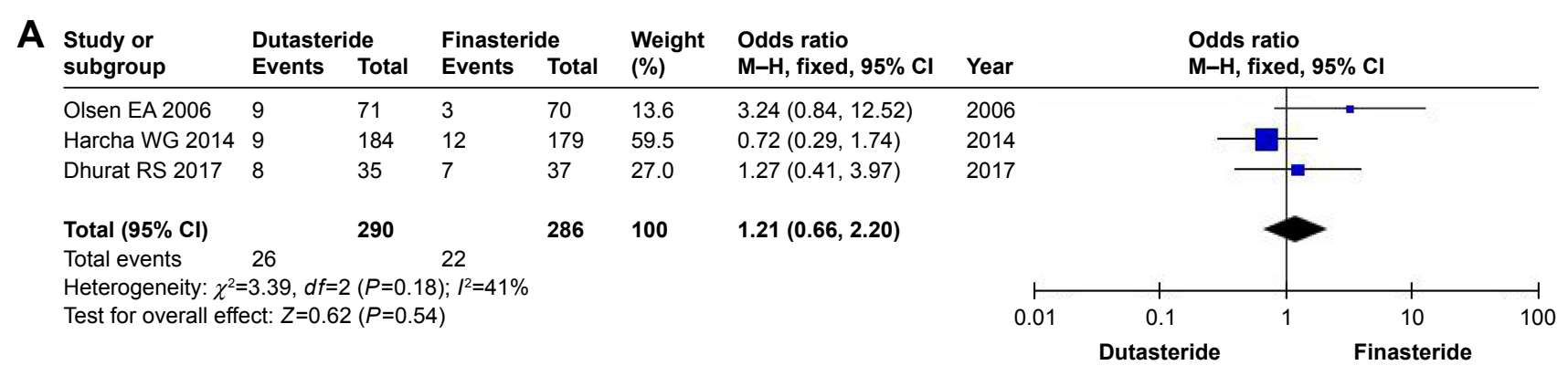

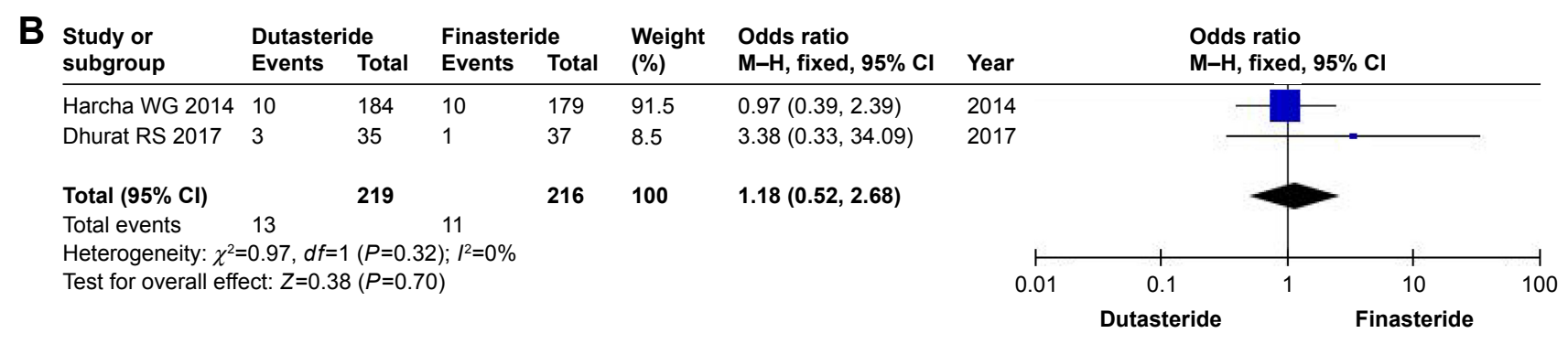

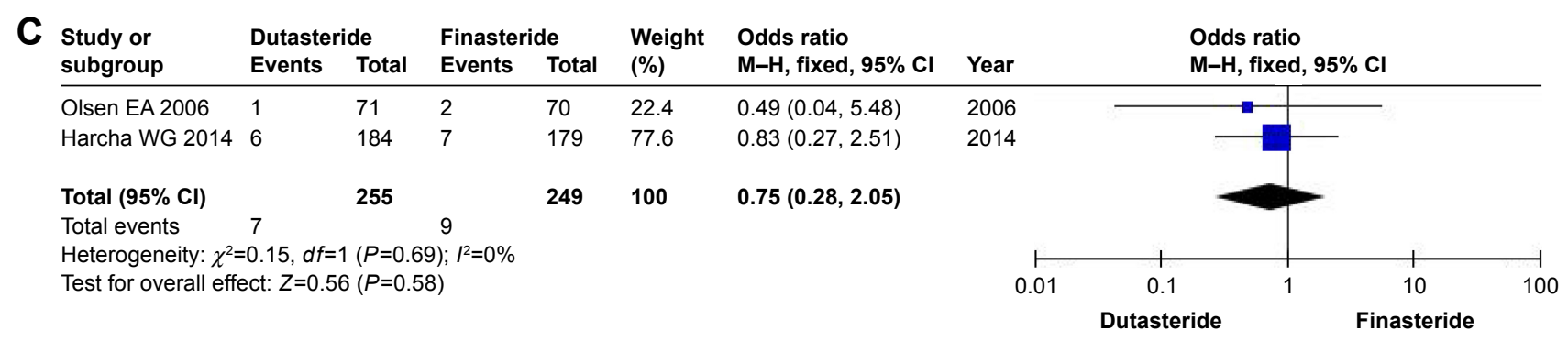

Figure 4 Forest plots showing changes in (A) altered libido, (B) erectile dysfunction, and (C) ejaculation disorders. Abbreviation: $\mathrm{M}-\mathrm{H}$, Mantel-Haenszel.

loss with age, eventually leading to passive psychological effects including self-conscious preoccupation, worries about aging, helplessness, and feelings of descending attractiveness..$^{20,21}$ This prompts the need for alternate treatment modality.

5AR can transform testosterone to DHT which is the major androgen involved in the pathological process of male AGA..$^{22}$ Therefore, inhibiting the activity of 5AR becomes an important treatment method for AGA. Clinically, both dutasteride and finasteride, as two kinds of 5ARI, have performed certain curative effects. One study discovered that dutasteride was approximately three times more potent than finasteride in inhibiting type $25 \mathrm{AR}$ and 100 times more potent in inhibiting type $15 \mathrm{AR} .{ }^{23}$ After studying the mechanism of action of two drugs, dutasteride was found to be theoretically more effective than finasteride in treating AGA.

We performed this meta-analysis to evaluate the safety and efficacy of dutasteride and finasteride in treating AGA during a 24-week treatment cycle, and found significant differences between the two drugs for the mean change in total hair count, investigator's assessment of global photographs for the vertex and frontal views, panel global photographic assessment for the vertex and frontal views, and subjects' assessment. The result showed that dutasteride was more effective than finasteride in all respects for the treatment of AGA. Besides, current data illustrated that the mean change from baseline in the subjects' assessment score was significantly higher in the dutasteride than in the finasteride group. However, two RCTs ${ }^{16,17}$ showed that there was no statistical significance in self-assessment of size of vertex spot, hair shedding, and hair quality between the two groups with the exception of hair loss on top of scalp.

Scalp DHT can inhibit the expression of Wnt $/ \beta$-catenin and generate a passive feedback in notch signaling, which results in miniaturization of the hair follicle. ${ }^{24}$ Therefore, lowering scalp DHT levels has become an important step to treat AGA. A related clinical study stated that $0.5 \mathrm{mg}$ /day of dutasteride could lower scalp DHT levels by more than $51 \%$, and $5 \mathrm{mg} /$ day of finasteride could lower scalp DHT levels by $\sim 41 \%{ }^{25,26}$ Our results proved the efficacy revealed 
by previous studies, meanwhile emphasizing the status of scalp DHT in the nosogenesis of AGA.

The present study showed that dutasteride and finasteride were relatively well-tolerated. Considering possible sexual dysfunction, mainly including altered libido, ED, and ejaculation disorders, the dutasteride group showed no statistical differences compared with the finasteride group. However, Debruyne et $\mathrm{al}^{27}$ found that dutasteride would have a better tolerance and fewer adverse events after a 4-year course of treatment. Andriole et $\mathrm{al}^{28}$ reported that long-term use of dutasteride might increase the risk of the progression of prostate cancer. As our study is a meta-analysis of shortterm treatment, the above-mentioned views could not be supported. According to the current analysis of the safety of the two drugs, the application of two drugs should be carefully considered for young middle-aged men, especially for patients who are sexually active.

Clinical reports found that 5ARI could independently improve the occurrence rate of ED, but many clinicians believed that the side effects of 5ARI would gradually disappear with ongoing treatment. ${ }^{29,30}$ There is considerable controversy about the severity and duration of ED induced by both drugs. Kaufman et $\mathrm{al}^{31}$ found that adverse reactions related to sexual functions most commonly occurred in year 1 of treatment with finasteride and placebo $(4.4 \%$ vs $2.2 \%)$; on the contrary, the incidence of adverse reactions decreased in year $5(0.6 \%$ vs $0 \%$ for finasteride and placebo, respectively). Therefore, this may indicate that there was no increase in the incidence of adverse reactions related to sexual functions during the course of long-term finasteride treatment. A Phase III trial followed for 4 years demonstrated that dutasteride therapy was well-tolerated over 4 years, with a general trend toward a reduction in incidence of the most common sexual adverse reactions over time $(6.0 \%$ in year 1 , $1.7 \%$ in year $2,1.4 \%$ in year 3 , and $0.4 \%$ in year 4$).{ }^{27}$ The adverse effects on sexual function decreased over time but persisted, which may have a negative impact on the patient's body and mind. Due to the limitation of follow-up period, more studies are needed to explain this concept.

Above all, dutasteride seems to provide a better efficacy compared with finasteride, and two drugs appear to show similar rates of adverse reactions, especially with respect to sexual dysfunction. In terms of dosage, there is no uniform fixation for both drugs at present. Clinically, dutasteride ( $0.5 \mathrm{mg}$ per day) and finasteride ( $1 \mathrm{mg}$ per day) have been used by some doctors to treat AGA and have showed good therapeutic effect. Further clinical studies are needed to explain the effect of different dosage of drugs in treating AGA.
Our meta-analysis involved three RCTs and the quality of each RCT was high. We could not infer the long-term efficacy and tolerance of dutasteride and finasteride, and selection bias and publication bias may affect the final results of our study. So, it still needs a lot of substitution of head-to-head comparison to confirm our findings. More high-quality RCTs with suitable study cohorts are needed to ascertain the efficacy and tolerance of dutasteride and finasteride for the treatment of AGA.

\section{Conclusion}

Dutasteride seems to provide a better efficacy compared with finasteride in treating AGA. The two drugs appear to show similar rates of adverse reactions, especially with respect to sexual dysfunction.

\section{Acknowledgments}

This research did not receive any specific grant from funding agencies in the public, commercial, or not-for-profit sectors.

\section{Author contributions}

All authors contributed to data analysis, drafting or revising the article, gave final approval of the version to be published, and agree to be accountable for all aspects of the work.

\section{Disclosure}

The authors report no conflicts of interest in this work.

\section{References}

1. Su LH, Chen TH. Association of androgenetic alopecia with smoking and its prevalence among Asian men: a community-based survey. Arch Dermatol. 2007;143(11):1401-1406.

2. Han SH, Byun JW, Lee WS, et al. Quality of life assessment in male patients with androgenetic alopecia: result of a prospective, multicenter study. Ann Dermatol. 2012;24(3):311-318.

3. Wolff H, Fischer TW, Blume-Peytavi U. The diagnosis and treatment of hair and scalp diseases. Dtsch Arztebl Int. 2016;113(21):377-386.

4. Whiting DA. Male pattern hair loss: current understanding. Int $J$ Dermatol. 1998;37(8):561-566.

5. Inui S, Itami S. Molecular basis of androgenetic alopecia: from androgen to paracrine mediators through dermal papilla. J Dermatol Sci. 2011; 61(1):1-6.

6. Sato A, Takeda A. Evaluation of efficacy and safety of finasteride $1 \mathrm{Mg}$ in 3177 Japanese men with androgenetic alopecia. J Dermatol. 2012; 39(1):27-32.

7. Mysore V, Shashikumar BM. Guidelines on the use of finasteride in androgenetic alopecia. Indian J Dermatol Venereol Leprol. 2016; 82(2):128-134.

8. Price VH, Menefee E, Sanchez M, Kaufman KD. Changes in hair weight in men with androgenetic alopecia after treatment with finasteride (1 mg daily): three- and 4-year results. $J$ Am Acad Dermatol. 2006; 55(1):71-74.

9. Sinclair R. Male pattern androgenetic alopecia. BMJ. 1998;317(7162): 865-869.

10. Bramson HN, Hermann D, Batchelor KW, Lee FW, James MK, Frye SV. Unique preclinical characteristics of GG745, a potent dual inhibitor of 5AR. J Pharmacol Exp Ther. 1997;282(3):1496-1502. 
11. Moher D, Liberati A, Tetzlaff J, Altman DG, PRISMA Group. Preferred reporting items for systematic reviews and meta-analyses: the PRISMA statement. Ann Intern Med. 2009;151(4):264-269.

12. Jadad AR. Randomised Controlled Trials. London: BMJ Publishing Group; 1998.

13. Higgins JP, Green S, editors. Cochrane Handbook for Systematic Reviews of Interventions, version 5.1.0 [Internet]. The Cochrane Collaboration; 2011 [uptated March 2011; cited May 10, 2017]. Available from: www.cochrane-handbook.org. Accessed Aug 30, 2018.

14. Dersimonian R, Laird N. Meta-analysis in clinical trials. Control Clin Trials. 1986;7(3):177-188.

15. Gubelin Harcha W, Barboza Martínez J, Tsai TF, et al. A randomized, active- and placebo-controlled study of the efficacy and safety of different doses of dutasteride versus placebo and finasteride in the treatment of male subjects with androgenetic alopecia. J Am Acad Dermatol. 2014; 70(3):489-498.

16. Olsen EA, Hordinsky M, Whiting D, et al. The importance of dual 5alpha-reductase inhibition in the treatment of male pattern hair loss: results of a randomized placebo-controlled study of dutasteride versus finasteride. J Am Acad Dermatol. 2006;55(6):1014-1023.

17. Shanshanwal SJ, Dhurat RS. Superiority of dutasteride over finasteride in hair regrowth and reversal of miniaturization in men with androgenetic alopecia: a randomized controlled open-label, evaluator-blinded study. Indian J Dermatol Venereol Leprol. 2017;83(1):47-54.

18. Tang PH, Chia HP, Cheong LL, Koh D. A community study of male androgenetic alopecia in Bishan, Singapore. Singapore Med J. 2000; 41(5):202-205.

19. Yazdabadi A, Magee J, Harrison S, Sinclair R. The Ludwig pattern of androgenetic alopecia is due to a hierarchy of androgen sensitivity within follicular units that leads to selective miniaturization and a reduction in the number of terminal hairs per follicular unit. Br J Dermatol. 2008; 159(6):1300-1302.

20. Cash TF, Price VH, Savin RC. Psychological effects of androgenetic alopecia on women: comparisons with balding men and with female control subjects. J Am Acad Dermatol. 1993;29(4):568-575.

21. Cash TF. The psychological effects of androgenetic alopecia in men. J Am Acad Dermatol. 1992;26(6):926-931.
22. Traish AM. Negative impact of testosterone deficiency and $5 \alpha$-reductase inhibitors therapy on metabolic and sexual function in men. $A d v$ Exp Med Biol. 2017;1043:473-526.

23. Clark RV, Hermann DJ, Cunningham GR, Wilson TH, Morrill BB, Hobbs S. Marked suppression of dihydrotestosterone in men with benign prostatic hyperplasia by dutasteride, a dual 5alpha-reductase inhibitor. J Clin Endocrinol Metab. 2004;89(5):2179-2184.

24. Premanand A, Reena Rajkumari B. Androgen modulation of Wnt/ $\beta$-catenin signaling in androgenetic alopecia. Arch Dermatol Res. 2018; 310(5):391-399.

25. Roehrborn CG, Boyle P, Nickel JC, Hoefner K, Andriole G; ARIA3001 ARIA3002 and ARIA3003 Study Investigators. Efficacy and safety of a dual inhibitor of 5-alpha-reductase types 1 and 2 (dutasteride) in men with benign prostatic hyperplasia. Urology. 2002;60(3):434-441.

26. Dallob AL, Sadick NS, Unger W, et al. The effect of finasteride, a 5 alpha-reductase inhibitor, on scalp skin testosterone and dihydrotestosterone concentrations in patients with male pattern baldness. $J$ Clin Endocrinol Metab. 1994;79(3):703-706.

27. Debruyne F, Barkin J, van Erps P, et al. Efficacy and safety of longterm treatment with the dual 5 alpha-reductase inhibitor dutasteride in men with symptomatic benign prostatic hyperplasia. Eur Urol. 2004; 46(4):488-495.

28. Andriole GL, Bostwick DG, Brawley OW, et al. Effect of dutasteride on the risk of prostate cancer. N Engl J Med. 2010;362(13):1192-1202.

29. Haddad A, Jabbour M, Bulbul M. Phosphodiesterase type 5 inhibitors for treating erectile dysfunction and lower urinary tract symptoms secondary to benign prostatic hyperplasia: a comprehensive review. Arab J Urol. 2015;13(3):155-161.

30. Pinsky MR, Gur S, Tracey AJ, Harbin A, Hellstrom WJ. The effects of chronic 5-alpha-reductase inhibitor (dutasteride) treatment on rat erectile function. $J$ Sex Med. 2011;8(11):3066-3074.

31. Kaufman KD; Finasteride Male Pattern Hair Loss Study Group. Long-term (5-year) multinational experience with finasteride $1 \mathrm{Mg}$ in the treatment of men with androgenetic alopecia. Eur J Dermatol. 2002;12(1):38-49.
Clinical Interventions in Aging

\section{Publish your work in this journal}

Clinical Interventions in Aging is an international, peer-reviewed journal focusing on evidence-based reports on the value or lack thereof of treatments intended to prevent or delay the onset of maladaptive correlates of aging in human beings. This journal is indexed on PubMed Central, MedLine,

\section{Dovepress}

CAS, Scopus and the Elsevier Bibliographic databases. The manuscript management system is completely online and includes a very quick and fair peer-review system, which is all easy to use. Visit http://www.dovepress. com/testimonials.php to read real quotes from published authors. 